\title{
Skin Ulcer
}

National Cancer Institute

\section{Source}

National Cancer Institute. Skin Ulcer. NCI Thesaurus. Code C54247.

A circumscribed and often suppurating skin crater which usually includes loss of skin integ rity of the superficial skin or the mucous membranes. 